\title{
Search for alternative magnetic tunnel junctions based on all-Heusler stacks
}

\author{
Worasak Rotjanapittayakul, ${ }^{1}$ Jariyanee Prasongkit, ${ }^{2,3}$ Ivan Rungger, ${ }^{4,5}$ Stefano Sanvito, ${ }^{4}$ \\ Wanchai Pijitrojana, ${ }^{1}$ and Thomas Archer ${ }^{4, *}$ \\ ${ }^{1}$ Department of Electrical and Computer Engineering, Faculty of Engineering, Thammasat University, Bangkok, 10120, Thailand \\ ${ }^{2}$ Division of Physics, Faculty of Science, Nakhon Phanom University, Nakhon Phanom, 48000, Thailand \\ ${ }^{3}$ Thailand Center of Excellence in Physics, Commission on Higher Education, 328 Si Ayutthaya Road, Bangkok, 10400, Thailand \\ ${ }^{4}$ School of Physics and Centre for Research on Adaptive Nanostructures and Nanodevices, Trinity College Dublin, Dublin 2, Ireland \\ ${ }^{5}$ Materials Division, National Physical Laboratory, Teddington, TW11 OLW, United Kingdom
}

(Received 17 February 2016; revised manuscript received 21 May 2018; published 23 August 2018)

\begin{abstract}
By imposing the constraints of structural compatibility, stability, and a large tunneling magneto-resistance, we have identified the $\mathrm{Fe}_{3} \mathrm{Al} / \mathrm{BiF}_{3} / \mathrm{Fe}_{3} \mathrm{Al}$ stack as a possible alternative to the well-established $\mathrm{FeCoB} / \mathrm{MgO} / \mathrm{FeCoB}$ in the search for a novel materials platform for high-performance magnetic tunnel junctions. Various geometries of the $\mathrm{Fe}_{3} \mathrm{Al} / \mathrm{BiF}_{3} / \mathrm{Fe}_{3} \mathrm{Al}$ structure have been analyzed, demonstrating that a barrier of less than $2 \mathrm{~nm}$ yields a tunneling magneto-resistance in excess of $25000 \%$ at low bias, without the need for the electrodes to be half-metallic. Importantly, the presence of a significant spin gap in $\mathrm{Fe}_{3} \mathrm{Al}$ for states with $\Delta_{1}$ symmetry along the stack direction makes the TMR very resilient to high voltages.
\end{abstract}

DOI: 10.1103/PhysRevB.98.054425

\section{INTRODUCTION}

Spin valves displaying large tunnel magneto-resistance (TMR) have undoubtedly revolutionized the electronics industry and now form the central component of many technologies, the most successful device being the read heads in hard-disk drives [1]. Importantly, spin valves are set to become the central component of many devices of the future, such as magnetic random access memories and spin-torque oscillators. The major breakthrough was the fabrication of epitaxial $\mathrm{CoFeB} / \mathrm{MgO} / \mathrm{CoFeB}$ spin valves [2,3], which exploit coherent electronic tunneling $[4,5]$ to provide a large TMR even at room temperature. In practical devices the fabrication of $\mathrm{CoFeB} / \mathrm{MgO} / \mathrm{CoFeB}$ spin valves requires the growth of rather complex thin films stacks, including functional layers (e.g., for magnetic pinning) and seed layers necessary for the epitaxial growth. It is then desirable to enlarge the available materials platform beyond the $\mathrm{CoFeB} / \mathrm{MgO}$ system. However, despite a large effort in both industry and academia [6], no junction alternative to $\mathrm{CoFeB} / \mathrm{MgO} / \mathrm{CoFeB}$ has been adopted by the community. This is a significant deficiency, since little room is left for tuning the materials properties necessary for the development of new applications of the technology. It is therefore imperative to explore alternative materials combinations which offer more freedom to engineer the device properties.

Heusler alloys are a large class of binary $\left(X_{3} Z\right)$, ternary $\left(X_{2} Y Z\right)$, and quaternary $\left(X X^{\prime} Y Z\right)$ compounds with more than 1500 known members and an impressively wide range of properties [7]. Many elements can be incorporated into the Heusler structure, making it rich and tunable, and as such ideal for developing new technologies.

*archert@tcd.ie
One key example for the switching of tunnel junctions is the Gilbert damping, which is strong in the $\mathrm{FeCoB}$ system [8], restricting the maximum operational frequency. Many Heuslers including $\mathrm{Fe}_{3} \mathrm{Si}$ [9], $\mathrm{Co}_{2} \mathrm{FeSi}$ [10], and $\mathrm{Co}_{2} \mathrm{FeAl}$ [11] all show a significantly lower Gilbert damping in comparison to FeCoB. Unfortunately, to the best of our knowledge, the Gilbert damping of $\mathrm{Fe}_{3} \mathrm{Al}$, our most promising alternative material, has not been measured.

Several attempts have been made to substitute the magnetic electrodes of the $\mathrm{FeCoB} / \mathrm{MgO} / \mathrm{FeCoB}$ stack with Heusler magnets, and successes have been obtained by replacing one or both the electrodes with $\mathrm{Co}_{2} Y Z$, where $Y=\mathrm{Fe}, \mathrm{Mn}$ and $Z=\mathrm{Si}$, Al [12-15]. This body of works is summarized in Table I. To the best of our knowledge, the highest TMR observed was for $\mathrm{Co}_{2} \mathrm{MnSi} / \mathrm{MgO} / \mathrm{Co}_{2} \mathrm{MnSi}$, which displays a TMR ratio of $1,995 \%$ at $4 \mathrm{~K}$ [15]. In this system, however, the magnetoresistance is sensitive to temperature with the TMR reducing to $354 \%$ at room temperature [15]. Such temperature sensitivity suggests interfacial magnetic defects or secondary phases, which disrupt the coherent tunneling. Co and $\mathrm{Mn}$ can directly substitute into the rock-salt $\mathrm{MgO}$ structure with formation energies of $-3.0 \mathrm{eV}$ and $-4.0 \mathrm{eV}$, respectively [16], making substitutional $\mathrm{Mn}$ in the $\mathrm{MgO}$ lattice a likely culprit.

A second approach has been to construct all Heuslers giant magneto-resistance (GMR) stacks, where the spacer between the magnetic electrodes is a metal. The relevant literature is summarized in Table II. Although a MR has been demonstrated, it was found small for all the known experiments, so that further work is needed to explain these negative results in view of the large MR predicted by $a b$ initio calculations [33].

The question that we answer in this paper is the following: Given the wide variety of properties available in the Heusler class, is it possible to create an all-Heusler TMR junction with 
TABLE I. Magnetic tunnel junctions incorporating Heusler alloys electrodes reported to date. The TMR is provided for low temperature (LT: $2-16 \mathrm{~K}$ ) and room temperature (RT: $\sim 300 \mathrm{~K}$ ), whenever available.

\begin{tabular}{|c|c|c|c|}
\hline MTJ structure & $\mathrm{TMR}_{\mathrm{LT}}$ & $\mathrm{TMR}_{\mathrm{RT}}$ & Ref. \\
\hline $\mathrm{Co}_{2} \mathrm{MnAlSi} / \mathrm{MgO} / \mathrm{CoFe}$ & 600 & 180 & [17] \\
\hline $\mathrm{Co}_{2} \mathrm{MnSi} / \mathrm{MgO} / \mathrm{Co}_{2} \mathrm{MnSi}$ & 1,995 & 354 & [15] \\
\hline $\mathrm{Co}_{2} \mathrm{MnSi} / \mathrm{MgO} / \mathrm{CoFe}$ & 1,049 & 335 & [18] \\
\hline $\mathrm{Co}_{2} \mathrm{MnGe} / \mathrm{MgO} / \mathrm{CoFe}$ & 376 & 160 & [19] \\
\hline $\mathrm{Co}_{2} \mathrm{FeAl} / \mathrm{Mg}_{2} \mathrm{AlO}_{4} / \mathrm{CoFe}$ & 453 & 280 & [20] \\
\hline $\mathrm{Co}_{2} \mathrm{FeAl} / \mathrm{MgO} / \mathrm{Co}_{3} \mathrm{Fe}$ & - & 175 & [21] \\
\hline $\mathrm{Co}_{2} \mathrm{FeAl} / \mathrm{MgO} / \mathrm{CoFeB}$ & - & 53 & [22] \\
\hline $\mathrm{Co}_{2} \mathrm{FeAlSi} / \mathrm{MgO} / \mathrm{Co}_{2} \mathrm{FeAlSi}$ & 390 & 220 & [23] \\
\hline $\mathrm{Co}_{2} \mathrm{FeSi} / \mathrm{MgO} / \mathrm{Co}_{3} \mathrm{Fe}$ & - & 30 & [24] \\
\hline $\mathrm{Co}_{2} \mathrm{FeSi} / \mathrm{MgO} / \mathrm{CoFeB}$ & - & 90 & [25] \\
\hline $\mathrm{Co}_{2} \mathrm{FeSi} / \mathrm{BaO} / \mathrm{Fe}$ & - & 104 & [26] \\
\hline $\mathrm{Co}_{2} \mathrm{CrFeAl} / \mathrm{MgO} / \mathrm{CoFe}$ & 317 & 109 & [27] \\
\hline $\mathrm{Co}_{2} \mathrm{CrFeAl} / \mathrm{MgO} / \mathrm{Co}_{3} \mathrm{Fe}$ & 74 & 42 & [28] \\
\hline $\mathrm{Co}_{2} \mathrm{CrFeAl} / \mathrm{MgO} / \mathrm{Co}_{2} \mathrm{CrFeAl}$ & 238 & 60 & [29] \\
\hline $\mathrm{Mn}_{1.8} \mathrm{Co}_{1.2} \mathrm{Ga} / \mathrm{MgO} / \mathrm{CoFeB}$ & - & 11 & [30] \\
\hline $\mathrm{Fe}_{2} \mathrm{CrSi} / \mathrm{MgO} / \mathrm{CoFe}$ & - & 8 & [31] \\
\hline $\mathrm{Fe}_{2} \mathrm{CoSi} / \mathrm{MgO} / \mathrm{Co}_{3} \mathrm{Fe}$ & 262 & 159 & [32] \\
\hline
\end{tabular}

materials alternative to the $\mathrm{Fe} / \mathrm{MgO}$ system? In this work we will use simple design concepts and $a b$ initio calculations to screen candidates based on the symmetry filtering mechanism, which has been so successful for the $\mathrm{Fe} / \mathrm{MgO}$ junction. Our analysis returns the $\mathrm{Fe}_{3} \mathrm{Al} / \mathrm{BiF}_{3}$ system as a promising stack for large magnetoresistance with a strong TMR retention at high bias. The paper is organized as follows. We open our discussion by explaining the criteria that have brought us to focus on a particular Heusler alloys stack, by looking first at the barrier and then at the magnetic electrodes. Then we move to discuss the transport properties of several $\mathrm{Fe}_{3} \mathrm{Al} / \mathrm{BiF}_{3} / \mathrm{Fe}_{3} \mathrm{Al}$ junctions with different barrier thicknesses. We first look at the zero-bias properties and then move to the finite-bias ones. Finally we conclude.

\section{SCREENING THE MATERIALS}

\section{A. The tunnel barrier}

In order to propose a new junction we must satisfy a number of constraints, which we will use to screen candidate materials combinations. First, the barrier material must be a robust insulator and therefore must have a large band gap, $E_{\mathrm{g}}$. If we use a cutoff band gap of $2.5 \mathrm{eV}$, we will reduce the number of the candidate Heusler materials from over 300000 (these include

TABLE II. All-Heusler metallic junctions grown to date. The GMR [\%], $\Delta \mathrm{RA}\left[\mathrm{m} \Omega \cdot \mu \mathrm{m}^{2}\right]$ and the method (Exp. = experimental data, $a b$ initio $=$ theoretical prediction) are given.

\begin{tabular}{lcccc}
\hline \hline All Heusler structure & GMR & $\Delta \mathrm{RA}$ & Method & Ref. \\
\hline $\mathrm{Co}_{2} \mathrm{MnGe} / \mathrm{Rh}_{2} \mathrm{CuSn} / \mathrm{Co}_{2} \mathrm{MnGe}$ & 6.7 & 4 & Exp. & {$[34]$} \\
$\mathrm{Co}_{2} \mathrm{MnSi} / \mathrm{Ni}_{2} \mathrm{NiSi} / \mathrm{Co}_{2} \mathrm{MnSi}$ & - & 0.24 & Exp. & {$[35]$} \\
$\mathrm{Co}_{2} \mathrm{CrSi} / \mathrm{Cu}_{2} \mathrm{CrAl} / \mathrm{Co}_{2} \mathrm{CrSi}$ & $\sim 10^{6}$ & - & ab initio & {$[33]$} \\
\hline \hline
\end{tabular}

TABLE III. All possible insulating Heusler materials having a wide band gap, $E_{\mathrm{g}} \geqslant 2.5 \mathrm{eV}$. The Strukturbericht (SB) symbols, lattice constant $\left(a_{0}[\AA]\right)$, band gap $\left(E_{\mathrm{g}}[\mathrm{eV}]\right)$, tetragonal ratio $\left(c / a_{0}\right)$, and the method with which they have been investigated are given $($ Exp. $=$ experimental data, $a b$ initio $=$ theoretical prediction from AFLOW.org).

\begin{tabular}{|c|c|c|c|c|c|c|}
\hline Material & SB & $a_{0}$ & $E_{\mathrm{g}}$ & $c / a_{0}$ & Method & Ref. \\
\hline $\mathrm{BaBrCl}$ & $\mathrm{C} 1_{b}$ & 7.604 & 3.476 & - & $a b$ initio & [16] \\
\hline $\mathrm{BiF}_{3}$ & $\mathrm{DO}_{3}$ & 5.861 & 5.100 & 1.0 & Exp. & [42-44] \\
\hline $\mathrm{BrClSr}$ & $\mathrm{C} 1_{b}$ & 7.262 & 4.670 & - & $a b$ initio & [16] \\
\hline $\mathrm{BrClPb}$ & $\mathrm{C} 1_{b}$ & 7.251 & 3.090 & - & $a b$ initio & [16] \\
\hline $\mathrm{BrCaCl}$ & $\mathrm{C} 1_{b}$ & 6.973 & 4.386 & - & $a b$ initio & [16] \\
\hline $\mathrm{BrHgK}$ & $\mathrm{C} 1_{b}$ & 7.948 & 3.253 & - & $a b$ initio & [16] \\
\hline $\mathrm{Br}_{2} \mathrm{KLi}$ & $\mathrm{L} 2_{1}$ & 7.647 & 3.313 & - & $a b$ initio & [16] \\
\hline $\mathrm{Br}_{2} \mathrm{KNa}$ & $\mathrm{L} 2_{1}$ & 7.784 & 3.337 & - & $a b$ initio & [16] \\
\hline $\mathrm{Br}_{2} \mathrm{KTl}$ & $\mathrm{L} 2_{1}$ & 8.083 & 3.330 & - & $a b$ initio & [16] \\
\hline $\mathrm{Br}_{2} \mathrm{LiNa}$ & $\mathrm{L} 2_{1}$ & 7.251 & 3.045 & - & $a b$ initio & [16] \\
\hline $\mathrm{Cl}_{2} \mathrm{GaK}$ & $\mathrm{L} 2_{1}$ & 7.493 & 3.424 & - & $a b$ initio & [16] \\
\hline $\mathrm{Cl}_{2} \mathrm{GaNa}$ & $\mathrm{L} 2_{1}$ & 7.198 & 3.032 & - & $a b$ initio & [16] \\
\hline $\mathrm{Cl}_{2} \operatorname{InK}$ & $\mathrm{L} 2_{1}$ & 7.718 & 3.154 & 1.2 & $a b$ initio & {$[16,42]$} \\
\hline $\mathrm{Cl}_{2} \mathrm{KLi}$ & $\mathrm{L} 2_{1}$ & 7.230 & 4.293 & 1.0 & $a b$ initio & {$[16,42]$} \\
\hline $\mathrm{Cl}_{2} \mathrm{KNa}$ & $\mathrm{L} 2_{1}$ & 7.367 & 4.277 & - & $a b$ initio & [16] \\
\hline $\mathrm{Cl}_{2} \mathrm{KTl}$ & $\mathrm{L} 2_{1}$ & 7.749 & 3.801 & - & $a b$ initio & [16] \\
\hline $\mathrm{Cl}_{2} \mathrm{LiNa}$ & $\mathrm{L} 2_{1}$ & 6.793 & 4.194 & - & $a b$ initio & [16] \\
\hline $\mathrm{Cl}_{2} \mathrm{LiTl}$ & $\mathrm{L} 2_{1}$ & 7.397 & 3.281 & 1.2 & $a b$ initio & {$[16,42]$} \\
\hline $\mathrm{ClHgK}$ & $\mathrm{C} 1_{b}$ & 7.771 & 3.531 & - & $a b$ initio & [16] \\
\hline $\mathrm{ClKZn}$ & $\mathrm{C} 1_{b}$ & 7.637 & 3.107 & - & $a b$ initio & [16] \\
\hline $\mathrm{ClHgK}$ & $\mathrm{C} 1_{b}$ & 7.778 & 3.143 & - & $a b$ initio & [16] \\
\hline LiMgN & $\mathrm{C} 1_{b}$ & 4.955 & 3.200 & 1.0 & Exp. & [45] \\
\hline LiMgP & $\mathrm{C} 1_{b}$ & 6.005 & 2.430 & 1.0 & Exp. & [46] \\
\hline $\mathrm{LiNaS}$ & $\mathrm{C} 1_{b}$ & 6.100 & 3.120 & 1.0 & $a b$ initio & [47] \\
\hline LiNaSe & $\mathrm{C} 1_{b}$ & 6.390 & 2.700 & 1.0 & $a b$ initio & [47] \\
\hline TaIrGe & $\mathrm{C} 1_{b}$ & 5.967 & 3.360 & 1.0 & Exp. & [48] \\
\hline
\end{tabular}

those reported in literature and the hypothetical ones contained in the AFLOW.org database) [16] to just 26. Notably, only four of these have been grown experimentally before; the remaining 22 are only predicted from $a b$ initio calculations [16]. The 26 barrier candidates are shown in Table III. Note that the band gaps reported here are computed by density functional theory (DFT) in the generalized gradient approximation (GGA), therefore they are expected to be significantly smaller than the true quasiparticle band gap. As such our $E_{\mathrm{g}} \geqslant 2.5 \mathrm{eV}$ criterion effectively selects insulators with a band gap, which is likely to be significantly larger than $2.5 \mathrm{eV}$.

Next we consider the transport properties of the tunnel barrier. In epitaxial spin valves the magnitude of the TMR is determined by the symmetry matching between the evanescent wave functions in the insulating barrier and the Bloch wave functions for majority and minority spins in the magnetic electrodes. In particular the TMR will be large if such wavefunction symmetry match occurs for only one of the two spin species, i.e., if only one of the two spin species is transmitted with large probability $[4,5]$.

In order to further screen these candidate barrier materials we have performed electronic structure calculations using self-interaction-corrected $[36,37]$ DFT as implemented in the atomic-orbital-based code SIESTA [38]. In general the inclusion 
TABLE IV. Insulating Heusler materials with a band gap $E_{\mathrm{g}} \geqslant$ $2.5 \mathrm{eV}$. The Strukturbericht (SB) symbols, lattice constant ( $\left.a_{\exp }[\AA]\right)$, and experimental band gap $\left(E_{\mathrm{g}}[\mathrm{eV}]\right)$ are given. In the final column we report the symmetry of the slowest decaying state along the [001] direction, as calculated in this work.

\begin{tabular}{lcccc}
\hline \hline Material & $\mathrm{SB}$ & $a_{\exp }$ & $E_{\mathrm{g}}$ & Symmetry \\
\hline $\mathrm{BiF}_{3}$ & $\mathrm{D}_{3}[43]$ & $5.861[43]$ & $5.10[44]$ & $\Delta_{1}^{\mathrm{CB}-\mathrm{VB}}$ \\
$\mathrm{LiMgN}$ & $\mathrm{C}_{b}[45]$ & $4.955[45]$ & $3.20[45]$ & $\Delta_{5}^{\mathrm{CB}}, \Delta_{1}^{\mathrm{VB}}$ \\
$\mathrm{LiMgP}$ & $\mathrm{C}_{b}[46]$ & $6.005[46]$ & $2.43[46]$ & $\Delta_{5}^{\mathrm{CB}}, \Delta_{1}^{\mathrm{VB}}$ \\
$\mathrm{TaIrGe}$ & $\mathrm{C}_{b}[48]$ & $5.967[48]$ & $3.36[48]$ & $\Delta_{1}^{\mathrm{CB}}, \Delta_{2}^{\mathrm{VB}}$ \\
\hline \hline
\end{tabular}

of self-interaction corrections drastically improve the band gap of a broad range of insulators, and here it brings the calculated gap of the chosen Heusler barriers within $10 \%$ from the experimental one. Core electrons are treated with normconserving relativistic Troullier-Martin pseudopotentials [39], while multi- $\zeta$ numerical atomic orbitals are used to represent the electron density and all the operators. Total energies are computed on a uniform real-space grid with an equivalent cutoff of $600 \mathrm{Ry}$, while the primitive unit cells are sampled with a $8 \times 8 \times 8 k$-point mesh over the Brillouin zone. The linear response conductance is calculated with the DFT-based nonequilibrium Green's functions code SMEAGOL [40,41], where the typical $k$-point sampling for a given heterojunction is $100 \times 100 \times 1$.

For each of the insulators we determine the symmetry of the slowest decaying state along the [001] direction, and we restrict ourselves to the experimentally verified insulating Heusler alloys, namely, $\mathrm{BiF}_{3}, \mathrm{LiMgN}, \mathrm{LiMgP}$, and TaIrGe. Our results are presented in Table IV, where we list the experimental structural parameters and quasiparticle band gap, together with the symmetry of the evanescent wave function with the slowest decay across the barrier. Notably, while for $\mathrm{BiF}_{3}$ there is only one low-lining complex band crossing the band gap, this is not the case for the other three alloys. In fact, for $\mathrm{LiMgN}, \mathrm{LiMgP}$, and TaIrGe the symmetry of the valence band maximum (VBM) and conduction band minimum (CBM) is different. This means that there is not a single complex band bridging the band gap, since the one starting at the VBM (CBM) does not end at the CBM (VBM). As such, the symmetry of the slowest decaying state across the barrier depends upon the exact position of the Fermi level in the hypothetical junction, namely, on the band alignment. This situation is not desirable in a tunneling junction [49]. When all these features are brought together, $\mathrm{BiF}_{3}$ appears as our best candidate. Its band structure is illustrated in Fig. 1(d).

$\mathrm{BiF}_{3}$ is the naturally occurring mineral gananite, which has been reported to have $\mathrm{a} \mathrm{DO}_{3}$ structure and a lattice parameter of $5.861 \AA$ [43]. The F atoms occupy the $4 a, 4 b$, and $4 c$ Wyckoff positions, while $\mathrm{Bi}$ is accommodated in the $4 d$. Gananite is a wide band-gap insulator with an experimentally observed optical gap of $\sim 5.10 \mathrm{eV}$ [44]. Theoretical band gaps of 3.81 and $3.94 \mathrm{eV}$ were calculated with the LDA (at the LDA lattice constant of $a_{0}^{\mathrm{LDA}}=5.865 \AA$ ) [50] and the GGA (at the GGA lattice constant of $a_{0}^{\mathrm{GGA}}=5.860 \AA$ ) [51,52], respectively. In this work the atomic self-interaction correction (ASIC) scheme
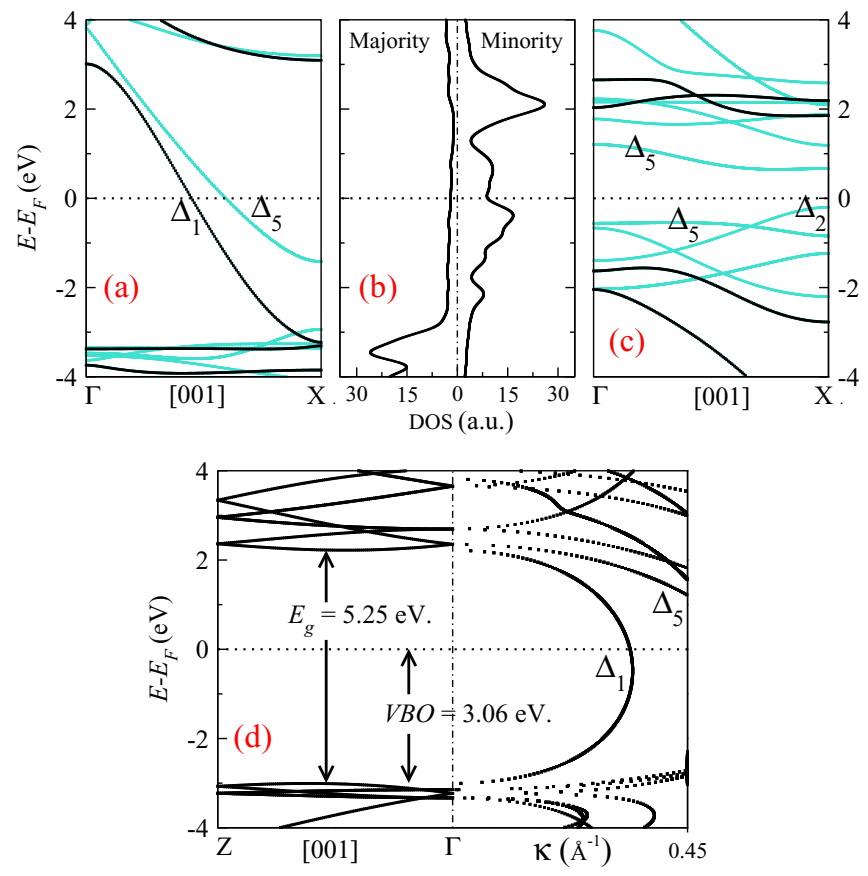

FIG. 1. Electronic structure of $\mathrm{Fe}_{3} \mathrm{Al}$ and $\mathrm{BiF}_{3}$ along the device stack direction, [001]. Panels (a), (b), and (c) are the majority band structure, the density of states, and the minority band structure for $\mathrm{DO}_{3}-\mathrm{Fe}_{3} \mathrm{Al}$, respectively. The bold lines represent the $\Delta_{1}$ bands. Panel (d) displays the complex band structure of the bulk $\mathrm{BiF}_{3}$.

built on top of the LDA returns a value of $5.25 \mathrm{eV}\left(a_{0}^{\mathrm{ASIC}}=\right.$ $5.836 \AA$ ).

\section{B. The magnetic electrodes}

We now move to select the magnetic materials to be used as electrodes. A crude screening criterion is that the magnetic electrodes must be made of materials having a magnetic ordering temperature significantly higher than room temperature. Here we have chosen the cutoff to be $700 \mathrm{~K}$, a value that should be sufficient to ensure little magnetization degradation for temperatures around room temperature. Such a cutoff temperature reduces the number of candidates to the 20 alloys listed in Table $\mathrm{V}$.

Second, there should be a good lattice match between the magnetic electrodes and the insulator. This is a necessary condition to ensure the epitaxial grow of the stack, which in turn is necessary for the spin filtering. We set the tolerance for the lattice match to less than $1.5 \%$. Such match can be achieved either by having a one-to-one match between the insulator and the magnet (the two share the same crystallographic axes) or by rotating one of them by $45^{\circ}$ in the plane of the stack [here we consider only the (100) growth direction]. Table VI presents all the possible electrode (barrier) combinations having a lattice mismatch smaller than $1.5 \%$, with the $45^{\circ}$-rotated epitaxial structures being in gray.

From the table it is easy to note that there are only eight magnets presenting a lattice mismatch smaller than $1.5 \%$ with our chosen insulator, $\mathrm{BiF}_{3}$. Two of these, $\mathrm{Mn}_{2} \mathrm{CoGa}$ and $\mathrm{Mn}_{2} \mathrm{VAl}$, are $\mathrm{Mn}_{2}$-based Heusler alloys, which we exclude from further analysis. The reason for such exclusion is that 
TABLE V. Magnetic Heusler materials with a $T_{\mathrm{C}}$ greater than $700 \mathrm{~K}$ considered as potential electrode. We report the Strukturbericht (SB) symbols, the experimental lattice constant $\left(a_{\exp }[\AA]\right)$, the Curie temperature $\left(T_{\mathrm{C}}[\mathrm{K}]\right)$, and the magnetic order, $\mathrm{FM}=$ ferromagnetic, HFM = half-metal. Here "ferri" means that the magnetic order is ferrimagnetic, although the electronic structure is that of a half-metal.

\begin{tabular}{lccccc}
\hline \hline Material & $\mathrm{SB}$ & $a_{\text {exp }}$ & $T_{\mathrm{C}}$ & Magnetic ground state & Ref. \\
\hline $\mathrm{Fe}_{3} \mathrm{Al}$ & $\mathrm{D}_{3}$ & 5.793 & 713 & $\mathrm{FM}$ & {$[53]$} \\
$\mathrm{Fe}_{3} \mathrm{Si}$ & $\mathrm{D}_{3}$ & 5.553 & 840 & $\mathrm{FM}$ & {$[53]$} \\
$\mathrm{Fe}_{2} \mathrm{CoGe}$ & $\mathrm{D}_{3}$ & 5.780 & 925 & $\mathrm{FM}$ & {$[54]$} \\
$\mathrm{Fe}_{2} \mathrm{CoSi}$ & $\mathrm{D} 0_{3}$ & 5.645 & 1,025 & $\mathrm{FM}$ & {$[55]$} \\
$\mathrm{Fe}_{2} \mathrm{CuAl}$ & $\mathrm{A}_{2}$ & 5.830 & 875 & $\mathrm{FM}$ & {$[54]$} \\
$\mathrm{Fe}_{2} \mathrm{NiGe}$ & $\mathrm{A}_{2}$ & 5.761 & 750 & $\mathrm{FM}$ & {$[54]$} \\
$\mathrm{Fe}_{2} \mathrm{NiAl}$ & $\mathrm{L} 2_{1}$ & 5.778 & 965 & $\mathrm{FM}$ & {$[56]$} \\
$\mathrm{Fe}_{2} \mathrm{NiSi}$ & $\mathrm{D} 0_{3}$ & 5.671 & 755 & $\mathrm{FM}$ & {$[56]$} \\
$\mathrm{Co}_{2} \mathrm{MnAl}$ & $\mathrm{B} 2$ & 5.671 & 710 & $\mathrm{HMF}$ & {$[57]$} \\
$\mathrm{Co}_{2} \mathrm{MnSi}$ & $\mathrm{L} 2_{1}$ & 5.655 & 985 & $\mathrm{HMF}$ & {$[58]$} \\
$\mathrm{Co}_{2} \mathrm{MnGe}$ & $\mathrm{L} 2_{1}$ & 5.749 & 905 & $\mathrm{HMF}$ & {$[59]$} \\
$\mathrm{Co}_{2} \mathrm{MnSn}$ & $\mathrm{L} 2_{1}$ & 6.000 & 829 & $\mathrm{HMF}$ & {$[60,61]$} \\
$\mathrm{Co}_{2} \mathrm{FeSi}$ & $\mathrm{L} 2_{1}$ & 5.640 & 1100 & $\mathrm{HMF}$ & {$[62-64]$} \\
$\mathrm{Co}_{2} \mathrm{FeAl}$ & $\mathrm{B} 2$ & 5.737 & 1000 & $\mathrm{HMF}$ & {$[64-66]$} \\
$\mathrm{Co}_{2} \mathrm{FeGa}$ & $\mathrm{L} 2_{1}$ & 5.751 & 1100 & $\mathrm{HMF}$ & {$[60,64]$} \\
$\mathrm{Co}_{2} \mathrm{FeGe}$ & $\mathrm{L} 2_{1}$ & 5.743 & 981 & $\mathrm{HMF}$ & {$[64,67]$} \\
$\mathrm{Co}_{2} \mathrm{CrSi}$ & $\mathrm{L} 2_{1}$ & 5.647 & 747 & $\mathrm{HMF}$ & {$[68]$} \\
$\mathrm{NiMnSb} \mathrm{C} 1_{b}$ & 5.903 & 730 & $\mathrm{HMF}$ & {$[69]$} \\
$\mathrm{Mn}_{2} \mathrm{VAl}$ & $\mathrm{L} 2_{1}$ & 5.920 & 760 & $\mathrm{HMF}($ ferri) & {$[70]$} \\
$\mathrm{Mn}_{2} \mathrm{CoGa}$ & $\mathrm{L} 2_{1}$ & 5.873 & 740 & $\mathrm{HMF}($ ferri) & {$[71]$} \\
\hline \hline
\end{tabular}

often the ground state of $\mathrm{Mn}_{2}$-type alloys presents a complex magnetic structure with ferrimagnetic order between the crystallographic inequivalent $\mathrm{Mn}$ ions (e.g., see $\mathrm{Mn}_{3} \mathrm{Ga}$ )[72]. This is a situation which is not suitable for a spin valve. We also exclude the half-Heusler, NiMnSb, which has a half-metallic
TABLE VII. Magnetic Heuslers considered as potential electrodes. The Strukturbericht (SB) symbols, the experimental lattice constant $\left(a_{\exp }[\AA]\right)$, the magnetic moment per formula unit $\left(\mu_{\mathrm{S}}\left[\mu_{\mathrm{B}} /\right.\right.$ f.u. $\left.]\right)$, and the Curie temperature $\left(T_{\mathrm{C}}[\mathrm{K}]\right)$ are given. In the two final columns we show the band symmetry $\left(\Delta_{[001]}^{\sigma}\right.$ for spin $\sigma=\uparrow, \downarrow$ ) across the Fermi level along the [001] direction, which have been calculated in this work. For $\mathrm{Fe}_{3} \mathrm{Al}$ no minority spin band crosses the Fermi level along the [001] direction (note that globally $\mathrm{Fe}_{3} \mathrm{Al}$ is not a half-metal, but it is along [001]).

\begin{tabular}{lcccccc}
\hline \hline Material & $\mathrm{SB}$ & $a_{\exp }$ & $\mu_{\mathrm{S}}$ & $T_{\mathrm{C}}$ & $\Delta_{[001]}^{\uparrow}$ & $\Delta_{[001]}^{\downarrow}$ \\
\hline $\mathrm{Fe}_{3} \mathrm{Al} \mathrm{[53]}$ & $\mathrm{D}_{3}$ & 5.793 & 5.10 & 713 & $\Delta_{1}, \Delta_{5}$ & - \\
$\mathrm{Fe}_{2} \mathrm{CoGe}[54]$ & $\mathrm{D}_{3}$ & 5.780 & 5.40 & 925 & $\Delta_{1}, \Delta_{5}$ & $\Delta_{5}$ \\
$\mathrm{Fe}_{2} \mathrm{CuAl}[54]$ & $\mathrm{A}_{2}$ & 5.830 & 3.30 & 875 & $\Delta_{1}, \Delta_{5}$ & $\Delta_{5}$ \\
$\mathrm{Fe}_{2} \mathrm{NiGe}[54]$ & $\mathrm{A}_{2}$ & 5.761 & 4.29 & 750 & $\Delta_{1}, \Delta_{5}$ & $\Delta_{5}, \Delta_{2}, \Delta_{2^{\prime}}$ \\
$\mathrm{Fe}_{2} \mathrm{NiAl}[56]$ & $\mathrm{L} 2_{1}$ & 5.778 & 4.46 & 965 & $\Delta_{1}, \Delta_{5}$ & $\Delta_{2}, \Delta_{2^{\prime}}$ \\
\hline \hline
\end{tabular}

electronic structure, but it is prone to disorder that strongly modifies its magnetic properties [73]. The electronic structure of the remaining five electrode compounds has been calculated, the symmetry of the states at the Fermi-level has been analyzed, and it is summarized in Table VII. Given the symmetry of the relevant complex band in $\mathrm{BiF}_{3}$, the electrodes must present bands with $\Delta_{1}$ symmetry at the Fermi level for only one spin channel along the [001] direction. All five remaining candidates meet this criterion.

When looking at the electronic structure of the five remaining Fe-containing magnetic Heusler alloys, we notice that all of them present bands at the Fermi level with both $\Delta_{1}$ and $\Delta_{5}$ symmetry in the majority $(\uparrow)$ channel, while the symmetry of the minority one $(\downarrow)$ differentiates them. In two cases, $\mathrm{Fe}_{2} \mathrm{CoGe}$ and $\mathrm{Fe}_{2} \mathrm{CuAl}$, the minority Fermi surface is dominated by the $\Delta_{5}$ symmetry, while for other two, $\mathrm{Fe}_{2} \mathrm{NiAl}$ and $\mathrm{Fe}_{2} \mathrm{NiGe}$,

TABLE VI. Materials combinations presenting a lattice mismatch smaller than $1.5 \%$. This can be obtained with the barrier and the magnet sharing the same crystallographic axes, or by rotating one of them by $45^{\circ}$ (in gray).

\begin{tabular}{|c|c|c|c|c|c|c|c|c|c|}
\hline $\mathrm{Fe}_{3} \mathrm{Si}$ & & & & 1.3 & 1.1 & 1.0 & 0.9 & 1.2 & \\
\hline $\mathrm{Co}_{2} \mathrm{FeSi}$ & & & & & & & & 0.4 & 1.3 \\
\hline $\mathrm{Co}_{2} \mathrm{CrSi}$ & & & & & & & & 0.5 & 1.2 \\
\hline $\mathrm{Co}_{2} \mathrm{MnSi}$ & & & & & & & & 0.6 & 1.1 \\
\hline $\mathrm{Fe}_{2} \mathrm{NiSi}$ & & & & & & & & 0.9 & 0.8 \\
\hline $\mathrm{Co}_{2} \mathrm{FeAl}$ & & & & & & & & & 0.4 \\
\hline $\mathrm{Co}_{2} \mathrm{FeGe}$ & & & & & & & & & 0.5 \\
\hline $\mathrm{Co}_{2} \mathrm{MnGe}$ & & & & & & & & & 0.6 \\
\hline $\mathrm{Co}_{2} \mathrm{FeGa}$ & & & & & & & & & 0.6 \\
\hline $\mathrm{Fe}_{2} \mathrm{NiGe}$ & 1.4 & & & & & & & & 0.8 \\
\hline $\mathrm{Fe}_{2} \mathrm{NiAl}$ & 1.4 & & & & & & & & 1.1 \\
\hline $\mathrm{NiMnSb}$ & 0.7 & 1.1 & & & & & & & \\
\hline $\mathrm{Mn}_{2} \mathrm{VAl}$ & 1.0 & 0.8 & 1.4 & & & & & & \\
\hline $\mathrm{Co}_{2} \mathrm{MnSn}$ & & 0.6 & 0.1 & & & & & & \\
\hline
\end{tabular}


TABLE VIII. Calculated formation energy [16,42].

\begin{tabular}{lcc}
\hline \hline Atoms & $\begin{array}{c}\text { Lowest Heusler } \\
\text { formation energy (eV/atom) }\end{array}$ & $\begin{array}{c}\text { Lowest formation } \\
\text { energy (eV/atom) }\end{array}$ \\
\hline $\mathrm{Bi}, \mathrm{F}$ & $\mathrm{BiF}_{3}-2.22$ & - \\
$\mathrm{Al}, \mathrm{F}$ & $\mathrm{AlF}_{3}-2.11$ & - \\
$\mathrm{Fe}, \mathrm{F}$ & $\mathrm{FeF}_{3}-1.33$ & $\mathrm{FeF}_{2}-4.25$ \\
$\mathrm{~F}, \mathrm{Al}, \mathrm{Fe}$ & $\mathrm{F}_{2} \mathrm{AlFe}_{-}-0.78$ & - \\
$\mathrm{Fe}, \mathrm{Al}, \mathrm{F}$ & $\mathrm{FeAlF}_{2}-0.62$ & - \\
$\mathrm{Fe}, \mathrm{Al}$ & $\mathrm{Fe}_{3} \mathrm{Al}-0.22$ & - \\
\hline \hline
\end{tabular}

both $\Delta_{2}$ and $\Delta_{2^{\prime}}$ bands are present (in the case of $\mathrm{Fe}_{2} \mathrm{NiGe}$ there is also a $\Delta_{5}$ one). $\mathrm{Fe}_{3} \mathrm{Al}$ sets a case on its own, since there is a spin gap in the minority band. Note that this is not a complete spin gap, namely, $\mathrm{Fe}_{3} \mathrm{Al}$ is not a half-metal, but it is present along the (100) direction. For this reason, among the different possibilities, we have then chosen $\mathrm{Fe}_{3} \mathrm{Al}$ as electrode material. $\mathrm{Fe}_{3} \mathrm{Al}$ has high $T_{\mathrm{C}}(713 \mathrm{~K})[53]$ and only a $1.2 \%$ lattice mismatch to $\mathrm{BiF}_{3}$. It has a $\mathrm{DO}_{3}$ structure $(F m \overline{3} m), \mathrm{Fe}(\mathrm{I})$ atoms occupy the Wyckoff positions $4 a(0,0,0)$ and $4 b\left(\frac{1}{2}, \frac{1}{2}, \frac{1}{2}\right)$, while $\mathrm{Fe}(\mathrm{II})$ and $\mathrm{Al}$ atoms occupy the $4 c\left(\frac{1}{4}, \frac{1}{4}, \frac{1}{4}\right)$ and $4 d\left(\frac{3}{4}, \frac{3}{4}, \frac{3}{4}\right)$ ones, respectively.

In Figs. 1(a) and 1(c) we present the band structure for majority and minority spins along [001] (the proposed stack orientation). As we have seen, $\mathrm{BiF}_{3}$ filters states with $\Delta_{1}$ symmetry, which are present in $\mathrm{Fe}_{3} \mathrm{Al}$ only for the majority band. In fact, along the [001] direction ( $\Gamma \rightarrow \mathrm{X}$ in $k$-space) at $E_{\mathrm{F}}$ there is a wide $\Delta_{1}$ band originating from the $\mathrm{Al} 3 s$ and $\mathrm{Fe} 4 s$ states in the majority spin channel [Fig. 1(a)], and a band gap in the minority one [Fig. 1(c)]. The first $\Delta_{1}$ contributions for the minority spin appear at $\pm 1.5 \mathrm{eV}$ from $E_{\mathrm{F}}$, providing a $3 \mathrm{~V}$ window in which the device is expected to show a large TMR. Note that, as already mentioned, the material is not half-metal as the gap in the minority channel is only along the specific $\Gamma \rightarrow \mathrm{X}$ direction, as shown in Fig. 1(b).

\section{Secondary phases}

We now turn our attention to discuss the possibility of creating secondary phases or interfacial defects at the $\mathrm{Fe}_{3} \mathrm{Al} / \mathrm{BiF}_{3}$ interface. Our criterion for phase separation is that the two materials in the stack, namely, $\mathrm{Fe}_{3} \mathrm{Al}$ and $\mathrm{BiF}_{3}$, should be thermodynamically well separated from any other phase containing the same elements. If we assume that an epitaxial growth can be maintained, we have to verify their thermodynamic stability against other competing Heusler structures. In Table VIII we present the calculated formation energy of likely Heusler phases created with $\mathrm{Fe}, \mathrm{Al}, \mathrm{Bi}$, and $\mathrm{F}$. Here we have investigated all the possible site occupancies and distortions within the Heulser structure. We observe that the lowest energy of formation is for $\mathrm{BiF}_{3}$. Therefore, if the growth can be maintained in the Heusler structure, we would expect a clean junction to form. Importantly, there is no F-rich structure that also contains $\mathrm{Fe}$ with an energy of formation within $1 \mathrm{eV} /$ atom from that of $\mathrm{BiF}_{3}$, so Fe diffusion into the barrier is not likely reducing the probability that paramagnetic defects will be present to scatter the spin. However, if the growth quality is low, growth of non-Heusler phases becomes possible and $\mathrm{FeF}_{2}$ is likely to form.

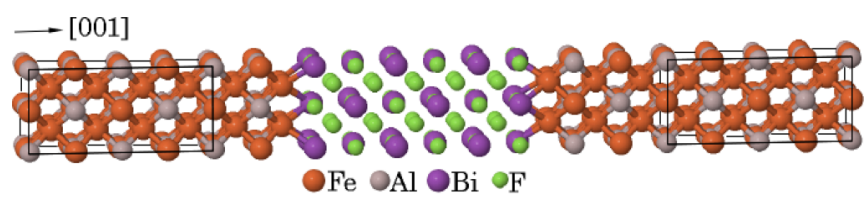

FIG. 2. Atomic structure of the all-Heusler $\mathrm{Fe}_{3} \mathrm{Al} / \mathrm{BiF}_{3} / \mathrm{Fe}_{3} \mathrm{Al}$ spin valve. The system is periodic in the plane orthogonal to [001], which defines the transport direction.

\section{THE ALL-HEUSLER $\mathrm{Fe}_{3} \mathrm{Al} / \mathrm{BiF}_{3} / \mathrm{Fe}_{3} \mathrm{Al}$ SPIN VALVE}

\section{A. Zero-bias properties}

The all-Heusler $\mathrm{Fe}_{3} \mathrm{Al} / \mathrm{BiF}_{3} / \mathrm{Fe}_{3} \mathrm{Al}$ spin valve is constructed by stacking $\mathrm{Fe}_{3} \mathrm{Al}(001)$ on $\mathrm{BiF}_{3}(001)$, as shown in Fig. 2. Its transport properties are now systematically investigated. For our transport calculations the in-plane lattice constant is fixed at $a_{0}=5.836 \AA$, equivalent to the theoretical cubic lattice constant of bulk $\mathrm{BiF}_{3}$. Fixing the in-plane lattice constant induces a small tetragonal distortion in the semiinfinite $\mathrm{Fe}_{3} \mathrm{Al}(001)$ leads with $c / a_{0}=1.124$ (the cell is relaxed to a forces tolerance of $10 \mathrm{meV} / \AA$ ). Such a distortion has negligible effects on the electronic structure of the electrodes. The interface energy, corrected for basis set superposition error, is found to be $3.78 \mathrm{~J} / \mathrm{m}^{2}$. To put this in context, the computed $\mathrm{Fe} / \mathrm{MgO}$ interface energy is reported to be $2.52 \mathrm{~J} / \mathrm{m}^{2}$ [74], namely, the $\mathrm{Fe}_{3} \mathrm{Al} / \mathrm{BiF}_{3}$ interface seems to be stronger than the $\mathrm{Fe} / \mathrm{MgO}$ one. The Fermi level of the junction is found to lie approximately in the middle of the $\mathrm{BiF}_{3}$ band gap, with a valence band offset of $3.06 \mathrm{eV}$, as shown in Fig. 1(d).

Electronic transport is calculated for three junctions with different $\mathrm{BiF}_{3}$ thicknesses, respectively, of $13.10,18.94$, and $24.77 \AA$. The zero-bias transmission coefficients as a function of energy, $T(E)$, are shown in Fig. 3 and clearly demonstrate that there is an exponential reduction of the transmission with the barrier thickness, confirming that the transport mechanism is indeed tunneling with little contribution from possible interface states.

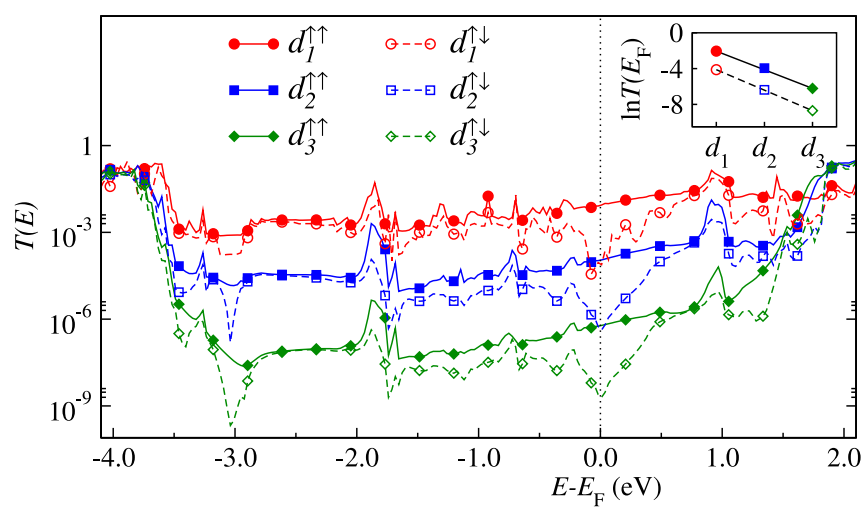

FIG. 3. Zero-bias transmission coefficient as a function of energy for the two configurations, where the magnetization vectors of the electrodes are either parallel $(\uparrow \uparrow)$ or antiparallel $(\uparrow \downarrow)$ to each other. Results are presented for three barrier thicknesses: $d_{1}=13.10 \AA$ (red lines), $d_{2}=18.94 \AA$ (blue lines), and $d_{3}=24.77 \AA$ (green lines). The inset shows the barrier thickness dependence of $T\left(E_{\mathrm{F}}\right)$. All results are obtained with a $100 \times 100 \mathrm{k}$-mesh. 


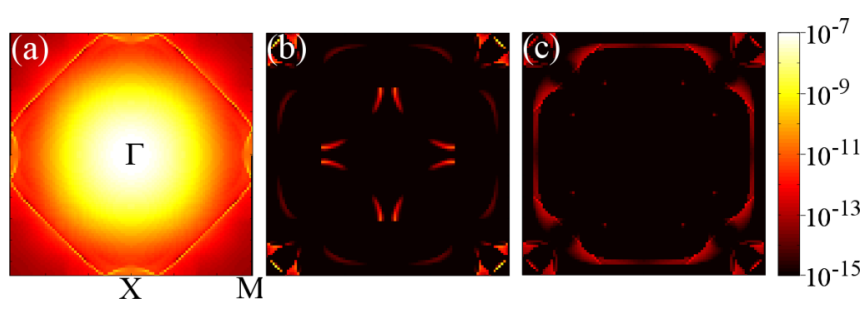

FIG. 4. $k_{\|}$-resolved transmission coefficient at the Fermi level for the all-Heusler junction with $\mathrm{a} \mathrm{BiF}_{3}$ barrier of $18.94 \AA$ A. (a) Majority spins parallel configuration, (b) minority spins parallel configuration, (c) antiparallel configuration. All results are obtained for a $100 \times$ $100 k$-mesh.

The various transmission coefficients for the [001] direction calculated at the Fermi level are plotted in Fig. 4 as a function of the $k$-vector in the two-dimensional Brillouin zone orthogonal to the transport direction. For the parallel configuration the transmission is dominated by the majority spins and a $k$-region around the $\Gamma$-point, while for the minority band and for the antiparallel configuration the transmission is small and originates from narrow pockets of $k$-vectors away from $\Gamma$. This further confirms that the transport is dominated by the $\Delta_{1}$ symmetry, present only for the majority spins. Importantly, the relative contribution to the total current of the majority spin channel relatively to the minority one in the parallel configuration will exponentially grow as the barrier thickness increases, meaning that for barriers thick enough the $\mathrm{Fe}_{3} \mathrm{Al} / \mathrm{BiF}_{3}$ system behaves as a half-metal, exactly as $\mathrm{Fe} / \mathrm{MgO}$.

\section{B. Finite-bias properties}

For the $18.94 \AA$-thick junction we have calculated the current and the TMR as a function of bias (see Fig. 5). Calculations are performed on a $24 \times 24 \times 1 k$-point mesh nonself-consistently (the potential drop is not self-consistently evaluated; see Ref. [75]) and have been verified against a

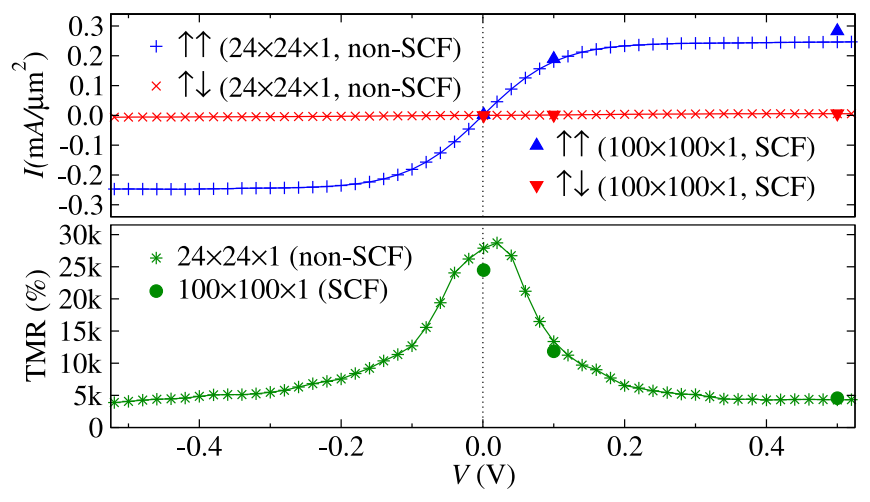

FIG. 5. Total current density, $I$, and TMR versus bias voltages, $V$, for the parallel and antiparallel magnetic configuration of the junction. Results are presented for a non-self-consistent calculation (the potential drop is not calculated self-consistently) using a $24 \times$ $24 k$-grid and confirmed by a self-consistent one obtained with a $100 \times 100$ mesh (closed symbols at voltages $V=0,0.1,0.5 \mathrm{~V}$ ). The $\mathrm{BiF}_{3}$ thickness is $18.94 \AA$.

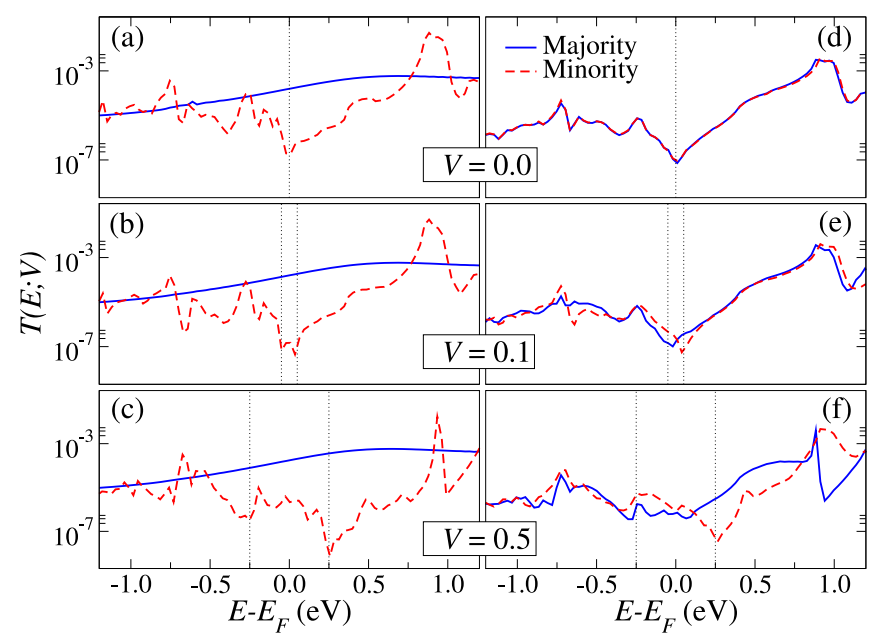

FIG. 6. Self-consistently calculated finite-bias transmission coefficient $T(E ; V)$ as a function of energy for the (a-c) parallel and $(\mathrm{d}-\mathrm{f})$ antiparallel magnetic configuration of the electrodes. The vertical dotted-lines are located at $E=E_{\mathrm{F}} \pm e V / 2$; namely, they enclose the bias window. Note that the transition remains spin degenerate only in the case of zero bias for the antiparallel configuration.

$100 \times 100 \times 1$ mesh for a self-consistent calculation at a few selected biases $(0,0.1$, and $0.5 \mathrm{~V})$. We find that the $I-V$ characteristic of the parallel configuration is approximately linear at low bias and then saturates at about $0.2 \mathrm{~V}$ to a value of $0.25 \mathrm{~mA} / \mu \mathrm{m}^{2}$. Since the same curve for the antiparallel configuration is flat and the current is small, the TMR as a function of bias decays from the $V \sim 0$ value of $25000 \%$ to about $5000 \%$ at $|V|>0.2 \mathrm{~V}$ [see below for $T(E ; V)$ ]. This is indeed a very encouraging result since an extremely large TMR can be reached for a $2 \mathrm{~nm}$ think barrier, and larger values can be obtained by making the barrier thicker. We must note that the theoretical TMR is for the perfect junction and demonstrates that symmetry filtering is the dominant mechanism. The actual TMR of any junction will depend on secondary phases or defects at the interface, so the values observed here should be considered an upper limit.

The transmission of the $\mathrm{Fe}_{3} \mathrm{Al} / \mathrm{BiF}_{3} / \mathrm{Fe}_{3} \mathrm{Al}$ junction has been self-consistently calculated at 0, 0.1, and 0.5 V. In Fig. 6 we present the transmission coefficient for each bias step, $T(E ; V)$. The behavior of the junction can be understood by considering the $\Delta_{1}$ filtering of $\mathrm{BiF}_{3}$ and the band structure of the $\mathrm{Fe}_{3} \mathrm{Al}$ electrodes. We see that when the magnetizations of the electrodes are parallel, $T(E ; V)$ for the majority spins is a smooth function of the energy, since the transmission originates from $\Delta_{1}$ band. At the same time there is no minority spin bands at the Fermi level along the [001] direction, resulting in a strongly suppressed minority transition around $E_{\mathrm{F}}$. As the bias voltage increases, bands with $\Delta_{5}, \Delta_{2}$, and $\Delta_{2^{\prime}}$ symmetry became available for transport. However, these are filtered by symmetry by the $\mathrm{BiF}_{3}$ barrier, and the transmission remains generally small. $T(E ; V)$ for the antiparallel configuration is essentially a convolution of those for the majority and minority spins in the parallel one, i.e., it traces closely the minority spin transmission. 


\section{CONCLUSION}

In conclusion, we have identified from all known and predicted Heusler alloys a materials combination which can act as an alternative to the $\mathrm{FeCoB} / \mathrm{MgO} / \mathrm{FeCoB}$ heterostructure. In particular we have looked at the $\mathrm{Fe}_{3} \mathrm{Al} / \mathrm{BiFe}_{3} / \mathrm{Fe}_{3} \mathrm{Al}$ stack and demonstrated that this junction operates with the same symmetry spin-filtering mechanism of $\mathrm{FeCoB} / \mathrm{MgO}$ and as such can display extremely high TMR values. Interestingly, the extended $\Delta_{1}$ spin gap along the (100) direction of $\mathrm{Fe}_{3} \mathrm{Al}$ gives us a large energy window where to expect a significant TMR. As such for this proposed junction we expect a strong TMR retention at high voltage.

\section{ACKNOWLEDGMENTS}

This work was supported by the Higher Education Research Promotion and National Research University Project of Thailand, the Office of the Higher Education Commission, the Thailand Research Fund (MRG5980185), the Science Foundation of Ireland (14/IA/2624), and by financial support from the European Union's Horizon 2020 PETMEM and TRANSPIRE projects. The authors wish to acknowledge the SFI/HEA Irish Centre for High-End Computing (ICHEC) and the Trinity Centre for High Performance Computing (TCHPC) for the provision of computational facilities and support.
[1] S. Ikeda, J. Hayakawa, Y. M. Lee, F. Matsukura, Y. Ohno, T. Hanyu, and H. Ohno, IEEE Trans. Electron. Devices 54, 991 (2007).

[2] S. Yuasa, T. Nagahama, A. Fukushima, Y. Suzuki, and K. Ando, Nat. Mater. 3, 868 (2004).

[3] S. S. P. Parkin, C. Kaiser, A. Panchula, P. Rice, B. Hughes, M. Samant, and S. Yang, Nat. Mater. 3, 862 (2004).

[4] W. H. Butler, X.-G. Zhang, T. C. Schulthess, and J. M. MacLaren, Phys. Rev. B 63, 054416 (2001).

[5] J. Mathon and A. Umerski, Phys. Rev. B 63, 220403 (2001).

[6] A. Hoffmann and S. D. Bader, Phys. Rev. Appl. 4, 047001 (2015)

[7] T. Graf, C. Felser, and S. S. P. Parkin, Prog. Solid State Chem. 39, 1 (2011).

[8] T. Devolder, P.-H. Ducrot, J.-P. Adam, I. Barisic, N. Vernier, J. Kim, B. Ockert, and D. Ravelosona, Appl. Phys. Lett. 102, 022407 (2013).

[9] Y. Ando, K. Ichiba, S. Yamada, E. Shikoh, T. Shinjo, K. Hamaya, and M. Shiraishi, Phys. Rev. B 88, 140406 (2013).

[10] C. Sterwerf, S. Paul, B. Khodadadi, M. Meinert, J. Schmalhorst, M. Buchmeier, C. K. A. Mewes, T. Mewes, and G. Reiss, J. Appl. Phys. 120, 083904 (2016).

[11] A. Kumar, F. Pan, S. Husain, S. Akansel, R. Brucas, L. Bergqvist, S. Chaudhary, and P. Svedlindh, Phys. Rev. B. 96, 224425 (2017).

[12] N. Tezuka, N. Ikeda, F. Mitsuhashi, and S. Sugimoto, Appl. Phys. Lett. 94, 162504 (2009).

[13] W. Wang, E. Liu, M. Kodzuka, H. Sukegawa, M. Wojcik, E. Jedryka, G. H. Wu, K. Inomata, S. Mitani, and K. Hono, Phys. Rev. B 81, 140402(R) (2010).

[14] S. Tsunegi, Y. Sakuraba, M. Oogane, K. Takanashi, and Y. Ando, Appl. Phys. Lett. 93, 112506 (2008).

[15] H. X. Liu, Y. Honda, T. Taira, K. I. Matsuda, M. Arita, T. Uemura, and M. Yamamoto, Appl. Phys. Lett. 101, 132418 (2012).

[16] R. H. Taylor, F. Rose, C. Toher, O. Levy, K. Yang, M. B. Nardelli, and S. Curtarolo, Comp. Mater Sci. 93, 178 (2014).

[17] E. Ozawa, S. Tsunegi, M. Oogane, H. Naganuma, and Y. Ando, J. Phys.: Conf. Ser. 266, 012104 (2011).

[18] H.-X. Liu, Y. Honda, K.-I. Matsuda, M. Arita, T. Uemura, and M. Yamamoto, Jpn. J. Appl. Phys. 51, 093004 (2012).

[19] T. Taira, T. Ishikawa, N. Itabashi, K. I. Matsuda, T. Uemura, and M. Yamamoto, J. Phys. D 42, 084015 (2009).

[20] T. Scheike, H. Sukegawa, T. Furubayashi, Z. Wen, K. Inomata, T. Ohkubo, K. Hono, and S. Mitani, Appl. Phys. Lett. 105, 242407 (2014).
[21] N. Tezuka, N. Ikeda, S. Sugimoto, and K. Inomata, Appl. Phys. Lett. 89, 252508 (2006).

[22] Z. Wen, H. Sukegawa, S. Kasai, M. Hayashi, S. Mitani, and K. Inomata, Appl. Phys. Express 5, 063003 (2012).

[23] N. Tezuka, N. Ikeda, S. Sugimoto, and K. Inomata, Jpn. J. Appl. Phys. 46, L454 (2007).

[24] N. Tezuka, S. Okamura, A. Miyazaki, M. Kikuchi, and K. Inomata, J. Appl. Phys. 99, 08T314 (2006).

[25] T. Daibou, M. Shinano, M. Hattori, Y. Sakuraba, M. Oogane, Y. Ando, and T. Miyazaki, IEEE Trans. Magn. 42, 2655 (2006).

[26] J. Rogge, P. Hedwig, C. Sterwerf, and A. Hütten, IEEE Trans. Magn. 48, 3825 (2012).

[27] T. Marukame, T. Ishikawa, S. Hakamata, K. I. Matsuda, T. Uemura, and M. Yamamoto, Appl. Phys. Lett. 90, 012508 (2007).

[28] M. Yamamoto, T. Marukame, T. Ishikawa, K. Matsuda, T. Uemura, and M. Arita, J. Phys. D 39, 824 (2006).

[29] T. Marukame, T. Ishikawa, S. Hakamata, K. I. Matsuda, T. Uemura, and M. Yamamoto, IEEE Trans Magn. 43, 2782 (2007).

[30] T. Kubota, S. Mizukami, Q. L. Ma, H. Naganuma, M. Oogane, Y. Ando, and T. Miyazaki, J. Appl. Phys. 115, 17 C704 (2014).

[31] Y. P. Wang, G. C. Han, H. Lu, J. Qiu, Q.-J. Yap, R. Ji, and K. L. Teo, J. Appl. Phys. 114, 013910 (2013).

[32] C. Sterwerf, M. Meinert, J. M. Schmalhorst, and G. Reiss, IEEE Trans. Magn. 49, 4386 (2013).

[33] Z. Q. Bai, Y. H. Lu, L. Shen, V. Ko, G. C. Han, and Y. P. Feng, J. Appl. Phys. 111, 093911 (2012).

[34] K. Nikolaev, P. Kolbo, T. Pokhil, X. Peng, Y. Chen, T. Ambrose, and O. Mryasov, Appl. Phys. Lett. 94, 222501 (2009).

[35] Z. Q. Bai, Y. Q. Cai, L. Shen, G. C. Han, and Y. P. Feng, Appl. Phys. Lett. 102, 152403 (2013).

[36] C. D. Pemmaraju, T. Archer, D. Sánchez-Portal, and S. Sanvito, Phys. Rev. B 75, 045101 (2007).

[37] A. Filippetti, C. D. Pemmaraju, S. Sanvito, P. Delugas, D. Puggioni, and V. Fiorentini, Phys. Rev. B 84, 195127 (2011).

[38] J. M. Soler, E. Artacho, J. D. Gale, A. Garcìa, J. Junquera, P. Ordejón, and D. Sánchez-Portal, J. Phys.: Condens. Matter 14, 2745 (2002).

[39] N. Troullier and J. L. Martins, Phys. Rev. B 43, 1993 (1991).

[40] A. R. Rocha, V. M. Garcìa-Suárez, S. W. Bailey, C. J. Lambert, J. Ferrer, and S. Sanvito, Phys. Rev. B 73, 085414 (2006).

[41] I. Rungger and S. Sanvito, Phys. Rev. B 78, 035407 (2008).

[42] http://www.materials-mine.com

[43] F. Hund and R. Fricke, Z. Anorg. Allg. Chem. 258, 198 (1949). 
[44] T. J. Moravec, R. A. Skogman, and E. Bernal G., Appl. Opt. 18, 105 (1979).

[45] K. Kuriyama, K. Nagasawa, and K. Kushida, J. Cryst. Growth 237-239, 2019 (2002).

[46] K. Kuriyama, K. Kushida, and R. Taguchi, Solid State Commun. 108, 429 (1998).

[47] A. Roy, J. W. Bennett, K. M. Rabe, and D. Vanderbilt, Phys. Rev. Lett. 109, 037602 (2012).

[48] F. Yan, X. W. Zhang, Y. G. Yu, L. P. Yu, A. P. Nagaraja, T. Mason, and A. Zunger, Nat. Commun. 6, 7308 (2015).

[49] N. M. Caffrey, D. Fritsch, T. Archer, S. Sanvito, and C. Ederer, Phys. Rev. B 87, 024419 (2013).

[50] C. Ortiz, O. Eriksson, and M. Klintenberg, Comput. Mater. Sci. 44, 1042 (2009).

[51] Z. Yang, X. Wang, L. Liu, S. Yang, and X. Su, Comput. Mater. Sci. 50, 3131 (2011).

[52] Z. Yang, X. Wang, Y. Pei, L. Liu, and X. Su, Comput. Mater. Sci. 60, 212 (2012).

[53] T. J. Burch, K. Raj, P. Jena, V. Niculescu, J. I. Budnick, and W. B. Muir, Phys. Rev. B 19, 2933 (1979).

[54] T. Gasi, V. Ksenofontov, J. Kiss, S. Chadov, A. K. Nayak, M. Nicklas, J. Winterlik, M. Schwall, P. Klaer, P. Adler, and C. Felser, Phys. Rev. B 87, 064411 (2013).

[55] L. Hongzhi, Z. Zhiyong, M. Li, X. Shifeng, L. Heyan, Q. Jingping, L. Yangxian, and W. Guangheng, J. Phys. D 40, 7121 (2007).

[56] Y. J. Zhang, W. H. Wang, H. G. Zhang, E. K. Liu, R. S. Ma, and G. H. Wu, Physica B 420, 86 (2013).

[57] T. Ryba, Z. Vargova, J. Kovac, P. Diko, V. Kavecansky, S. Piovarci, C. Garcia, and R. Varga, IEEE Trans. Magn. 51, 1 (2015).

[58] H. Pandey, P. C. Joshi, R. P. Pant, R. Prasad, S. Auluck, and R. C. Budhani, J. Appl. Phys. 111, 023912 (2012).

[59] M. Belmeguenai, F. Zighem, Y. Roussigné, S. M. Chérif, P. Moch, K. Westerholt, G. Woltersdorf, and G. Bayreuther, Phys. Rev. B 79, 024419 (2009).
[60] P. J. Brown, K. U. Neumann, P. J. Webster, and K. R. A. Ziebeck, J. Phys.: Condens. Matter 12, 1827 (2000).

[61] C. Felser and G. Fecher, Spintronics: From Materials to Devices (Springer, London, 2013).

[62] S. Wurmehl, G. H. Fecher, H. C. Kandpal, V. Ksenofontov, C. Felser, H. J. Lin, and J. Morais, Phys. Rev. B 72, 184434 (2005).

[63] O. Gaier, J. Hamrle, S. Trudel, B. Hillebrands, H. Schneider, and G. Jakob, J. Phys. D 42, 232001 (2009).

[64] B. Balke, S. Wurmehl, G. H. Fecher, C. Felser, M. C. M. Alves, F. Bernardi, and J. Morais, Appl. Phys. Lett. 90, 172501 (2007).

[65] O. Gaier, J. Hamrle, S. Trudel, A. C. Parra, B. Hillebrands, C. H. E. Arbelo, and M. Jourdan, J. Phys. D 42, 084004 (2009).

[66] K. H. J. Buschow, P. G. van Engen, and R. Jongebreur, J. Magn. Magn. Mater. 38, 1 (1983).

[67] K. R. Kumar, K. K. Bharathi, J. A. Chelvane, S. Venkatesh, G. Markandeyulu, and N. Harishkumar, IEEE Trans. Magn. 45, 3997 (2009).

[68] X. Q. Chen, R. Podloucky, and P. Rogl, J. Appl. Phys. 100, 113901 (2006).

[69] C. N. Borca, T. Komesu, H. K. Jeong, P. A. Dowben, D. Ristoiu, Ch. Hordequin, J. P. Noziéres, J. Pierre, S. Stadler, and Y. U. Idzerda, Phys. Rev. B 64, 052409 (2001).

[70] C. Jiang, M. Venkatesan, and J. M. D. Coey, Solid State Commun. 118, 513 (2001).

[71] R. Y. Umetsu and T. Kanomata, J. Phys. Proc. 75, 890 (2015).

[72] K. Rode, N. Baadji, D. Betto, Y.-C. Lau, H. Kurt, M. Venkatesan, P. Stamenov, S. Sanvito, J. M. D. Coey, E. Fonda, E. Otero, F. Choueikani, P. Ohresser, F. Porcher, and G. André, Phys. Rev. B 87, 184429 (2013).

[73] D. Orgassa, H. Fujiwara, T. C. Schulthess, and W. H. Butler, J. Appl. Phys. 87, 5870 (2000).

[74] D. Wiśnios, A. Kiejna, and J. Korecki, Phys. Rev. B 92, 155425 (2015).

[75] N. Jutong, I. Rungger, C. Schuster, U. Eckern, S. Sanvito, and U. Schwingenschlögl, Phys. Rev. B 86, 205310 (2012). 